\title{
Introducing Glycerol as a Sustainable Solvent to Organolithium Chemistry: Ultrafast Chemoselective Addition of Aryllithium Reagents to Nitriles Under Air and at Ambient Temperature
}

\author{
María J. Rodríguez-Álvarez, ${ }^{[a]}$ Joaquín García-Álvarez, ${ }^{*[a]}$ Marina Uzelac, ${ }^{[b]}$ Michael Fairley, ${ }^{[b]}$ Charles T. \\ $\mathrm{O}^{\prime}$ Hara $^{[\mathrm{b}]}$ and Eva Hevia*[b]
}

\begin{abstract}
Edging closer towards developing air and moisture compatible polar organometallic chemistry, the chemoselective and ultrafast addition of a range of aryllithium reagents to nitriles has been accomplished using glycerol as a solvent, at ambient temperature in the presence of air, establishing a novel sustainable access to aromatic ketones. Addition reactions occur heterogeneously ("on glycerol conditions"), where the lack of solubility of the nitriles in glycerol and the ability of the latter to form strong intermolecular H-bonds seem key to favouring nucleophilic addition over competitive hydrolysis. Remarkably, PhLi exhibits a greater resistance to hydrolysis working "on glycerol" conditions than "on water". Introducing glycerol as a new solvent in organolithium chemistry unlocks a myriad of opportunities for developing more sustainable, air and moisture tolerant main-group-metal-mediated organic synthesis.
\end{abstract}

\section{Introduction}

Celebrating the 100 year anniversary since Schlenk and Holtz's discovery of them in 1917, organolithium compounds have been and remain pivotal to the development of synthetic chemistry. ${ }^{[1]}$ Staple reagents in academic laboratories worldwide, these centurions are in high demand in chemical industries that require manipulation of aromatic scaffolds (e.g., agrochemicals, pharmaceuticals). ${ }^{[2]}$ This extensive utilization reflects the high reactivity (and associated oxophilicity) of their Li-C bonds due largely to the substantial polarity separation between lithium and carbon. To control this reactivity therefore necessitates the imposition of severely restrictive protocols (e.g., moisture- and oxygen-free organic solvents, inert atmospheres, low temperatures etc.). ${ }^{[1]}$ Thus, running organolithium chemistry under aerobic and/or hydrous conditions, without the need of scrupulously dry toxic organic solvents, is one of the ultimate challenges for synthetic chemists working in this area. ${ }^{[3]}$

[a] M. J. Rodríguez-Álvarez, Dr. J. García-Álvarez Laboratorio de Compuestos Organometálicos y Catálisis (Unidad Asociada al CSIC). Centro de Innovación en Química Avanzada (ORFEO-CINQA)

Departamento de Química Orgánica e Inorgánica (IUQOEM)

Facultad de Química, Universidad de Oviedo,

E-33071, Oviedo, Spain.

E-mail: garciajoaquin@uniovi.es

[b] Dr. M. Uzelac, M. Fairley, Dr. C. T. O'Hara, Prof. E. Hevia WestCHEM, Department of Pure and Applied Chemistry University of Strathclyde, Glasgow, UK, G1 1XL

E-mail: eva.hevia@strath.ac.uk

Supporting information for this article is given via a link at the end of the document
Making inroads towards meeting this challenge, our groups have uncovered the potential of Deep Eutectic Solvents (DESs), combining the non-toxic and biorenewable ammonium salt choline chloride $(\mathrm{ChCl}),\left[\mathrm{Me}_{3} \mathrm{NCH}_{2} \mathrm{CH}_{2} \mathrm{OH}\right]^{+} \mathrm{Cl}^{-}$with water or glycerol $(\mathrm{Gly}),{ }^{[4]}$ as alternative green reaction media for highlypolarized organometallic compounds. ${ }^{[5,6]}$ Thus, we have reported the chemoselective alkylation of ketones by $\mathrm{RMgX}$ and $\mathrm{RLi}$ reagents at ambient temperature, under air and in protic DESs, a trio of conditions seemingly incompatible with polar organometallics, yet bizarrely these offer improved yields and better selectivities than under standard inert atmosphere protocols (Scheme 1). ${ }^{[5 a]}$ Interestingly, we have found the same behaviour for the chemoselective nucleophilic arylation/alkylation of non-activated imines. ${ }^{[6]}$ The DESs success has been attributed to the possible formation of kinetically-activated mixed-ammonium ate salts by cocomplexation of the polar reagents ( $\mathrm{RLi}$ or $\mathrm{RMgX})$ with choline chloride $(\mathrm{ChCl})$. In parallel with these studies, Capriati and coworkers $^{[7]}$ have demonstrated that Grignard and organolithium reagents can smoothly undergo nucleophilic additions to $\gamma$ chloroketones or imines "on water", ${ }^{[8]}$ competitively with protonolysis, under batch conditions at ambient temperature and in the presence of air.

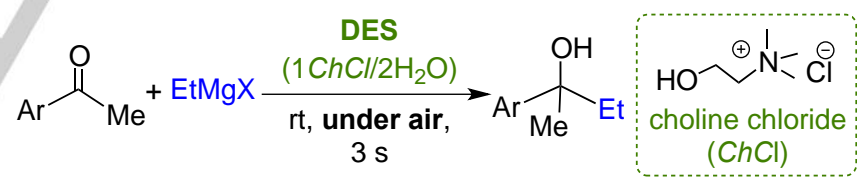

Scheme 1 Addition of $\mathrm{RMgX}$ reagents to ketones under air at ambient temperature using $\mathrm{ChCl}$-based DESs. ${ }^{[5 \mathrm{a}]}$

Biomass-derived solvents [e.g., 2-methyl-THF (Me-THF), lactic acid, $y$-valerolactone or glycerol] are also emerging as greener alternatives to volatile organic compounds (VOCs) in organic synthesis. ${ }^{[9]}$ Obtained as a major by-product of the biodiesel industry, ${ }^{[10]}$ glycerol (Gly) is a particularly appealing green solvent. ${ }^{[11]}$ Thus along with its exceptional physicochemical properties (i.e., high boiling point and polarity; low toxicity and flammability) and its ability to dissolve both inorganic or organic compounds, ${ }^{[11]}$ recent reports have shown that using Gly as a solvent can improve the selectivity/efficiency of organic transformations. ${ }^{[12]}$ Nevertheless, despite these key advantages, Gly has never been used as a solvent in organolithium chemistry, probably as a consequence of the common assumption that these polar reagents will rapidly decompose in this solvent through reaction with its acidic alcohol groups.

Taking an important step further on our journey to develop more sustainable polar organometallic chemistry, here we 
present a breakthrough in the addition of aryllithium reagents to aromatic nitriles to access a range of bis(aryl) ketones under air, at ambient temperature by introducing Gly as an environmentally benign solvent for these reaction classes. For comparison, the reactions have also been assessed using water as a solvent.

\section{Results and Discussion}

To begin, we selected as a model reaction the addition of phenyllithium (PhLi) to benzonitrile ${ }^{[13]}$ (1a) at ambient temperature, in air and using different stoichiometries in Gly as solvent (Scheme 2). Remarkably, the high yield (85\%) and almost instantaneous ( $3 \mathrm{~s}$ ) formation of benzophenone imine (2a) was observed when 2 eq. of PhLi were used. It is important to note that firstly, using a larger excess of $\mathrm{PhLi}$ (2.5-3.0 equivalents) does not improve the yield of benzophenone imine (2a), but produces small amounts of biphenyl and phenol as byproducts; and secondly, that formation of the tertiary carbamine (triphenylmethanamine) through double addition of $\mathrm{PhLi}$ to benzonitrile was not observed. ${ }^{[14]}$ However the most remarkable aspect of this reaction is that the use of inert-atmosphere Schlenk techniques or low temperatures, i.e., standard reaction conditions for manipulating organolithium reagents, is not required.

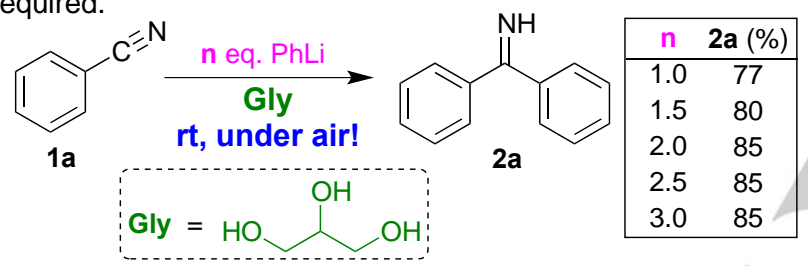

Scheme 2 Study of the addition reaction of PhLi to benzonitrile (1a) employing different stoichiometries in Gly as solvent (yields determined by GC analysis of reaction mixtures using a calibration curve).

Table 1. Addition reaction of polar organometallic reagents (RM) to benzonitrile (1a) in different green solvents. ${ }^{[a]}$

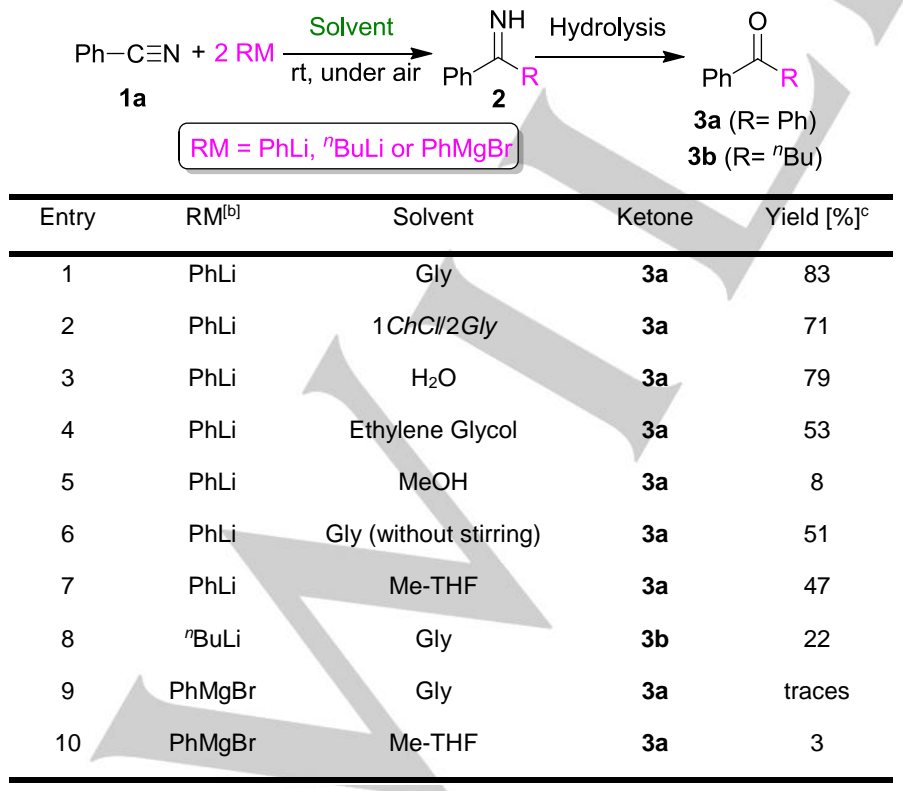

[a] Reactions were performed under air, at ambient temperature and using 0.5 $\mathrm{g}$ of the solvent. $0.5 \mathrm{mmol}$ of benzonitrile (1a) was utilised throughout. ${ }^{[b]}$ Commercial solution of $\mathrm{PhLi}$ (1.9 M in dibutyl ether), ${ }^{\mathrm{n} B u L i}$ (1.6 $\mathrm{M}$ in hexanes) and $\mathrm{PhMgBr}$ (1.0 $\mathrm{M}$ in THF) were used. [c] Yields determined by ${ }^{1} \mathrm{H}$ NMR spectroscopy using $\mathrm{CH}_{2} \mathrm{Br}_{2}$ as an internal standard.
One pot acidic hydrolysis ${ }^{[15]}$ of $\mathbf{2 a}$ led to the formation of benzophenone (3a) in an $83 \%$ yield under standard bench conditions (Table 1, entry 1). Thus, we envisioned that a modular combination of the PhLi addition to nitriles in Gly with the in situ hydrolysis of the relevant imine should allow us to design a straightforward, one-pot method to prepare a library of structurally diverse ketones under mild, simple and environmentally friendly reaction conditions (see Tables 1 and 2).

Ketone 3a was obtained in comparable yields using bulk Gly as a solvent and its chloride-based eutectic mixture $1 \mathrm{ChCl/2Gly}$ (83 and $71 \%$ yield respectively, entries $1-2$, Table 1 ). It should be noted that benzonitrile (1a) is sparingly soluble in both reaction media, and the reactions take place under heterogeneous conditions, when a completely immiscible ethereal solution of $\mathrm{PhLi}$ is added to a suspension of $\mathbf{1 a}$ in Gly. A similar scenario has been reported by Capriati using organolithium and Grignard reagents in heterogeneous aqueous media, ${ }^{[7]}$ with addition reactions taking place "on water" conditions ${ }^{[8]}$ rather than in the reaction medium, preferentially furnishing the relevant addition products instead of the hydrolysis of the organometallic reagent. "On water" reactions are thought to occur at the organic/liquid water interface with water insoluble reactants. ${ }^{[8 \mathrm{c}]}$ To try to verify this "on glycerol" assumption we run in parallel three sets of reactions under the previously optimised reaction conditions (2 eq. of $\mathrm{PhLi}$, ambient temperature and under air). Thus, firstly we replace glycerol by the another protic medium (water, entry 3 ) in which benzonitrile is insoluble. ${ }^{[7 b]}$ Under these "heterogeneous" conditions the expected ketone 3 a could also be produced in good yields (79\%, entry 3), without observing the expected protonation of $\mathrm{PhLi}$ as a competing process. Moreover and in the same line, we observed experimentally a direct relationship between the solubility of benzonitrile in other protic and alcoholic reaction media [ethylene glycol (EG) partially soluble; $\mathrm{MeOH}$ totally soluble] and reaction yield (53 and $8 \%$ respectively, entries $4-5$ ), which suggest a key role for the solubility of the reactant in promoting these addition reactions. The ability of these alcohols to engage in $\mathrm{H}$-bonding should also be considered, with that of $\mathrm{MeOH}$ being significantly more limited than those reported for Gly or water, ${ }^{[16]}$ which can also favour the competing hydrolysis of $\mathrm{PhLi}$ over the addition process. Thus, using Me-THF as a solvent, in which $1 \mathrm{a}$ is completely soluble, under air and at ambient temperature, afforded $3 a$ in a $47 \%$ yield (entry 7 ).

Further support for "on Gly" reactivity was found when PhLi addition to 1a was performed in Gly with no stirring. Previous reports have shown that the yields of "on water" reactions can be affected by stirring/agitation effects since they can influence the volume and surface area of the organic droplets. ${ }^{[8 c]}$ Under these conditions, the yield for 3 a dropped to $51 \%$ (entry 6 ).

The reactivity of 1a with other polar organometallics (RLi or $\mathrm{RMgX}$ ) under the optimized reaction conditions (2 eq., ambient temperature, under air) was also investigated using glycerol as solvent. In this sense, aliphatic and more basic organolithium reagent ( ${ }^{n} \mathrm{BuLi}$, entry 8 ) yielded the expected butylated ketone $\mathbf{3 b}$ in a modest $22 \%$ yield. Replacing Gly by water afforded $\mathbf{3 b}$ in a slightly improved $37 \%$ yield. These findings contrast with recent work by Capriati for additions of alkyl organolithiums (e.g. "BuLi) to nitriles under "on water" conditions, which in the presence of allyl Grignard reagents allows access to tertiary carbimines. ${ }^{[7 \mathrm{~b}]}$

The less reactive Grignard reagent $\mathrm{PhMgBr}$ failed to produce $3 \mathbf{a}$ under the optimized reaction conditions (entry 9), 
suggesting that the higher polarity of $\mathrm{Li}-\mathrm{C}$ bonds in $\mathrm{RLi}$ reagents (versus C-Mg bonds) is crucial for success in the addition process. ${ }^{[17]}$ This lack of reactivity was also observed when using Me-THF under air at ambient temperature (entry 10). Remarkably the reaction of PhLi with $\mathrm{PhCN}$ can also be scaledup to $5 \mathrm{mmol}$ scale (using $5 \mathrm{~g}$ of Gly as a solvent), yielding ketone $3 \mathbf{a}$ in a $78 \%$ yield (see Fig S! 2 in SI for details).

Stimulated by these preliminary results, we next assessed the scope of this methodology extending our studies to a range of nitriles (1a-i) using Gly or water as solvents. As shown in Table 2 and regardless of the solvent employed, in most cases, the nitriles tested led to the efficient and almost instantaneous ( 3 s) addition reaction with high chemoselectivity, as only unreacted nitrile and the final ketone (3a-j) were observed in the reaction crudes. Comparing the yields observed using water and Gly as a solvent an interesting trend emerges. For liquid aromatic nitriles (entries 1-8, Table 2) excellent and comparable yields are observed for both reaction media (76-86\%). However for solid nitriles (entries 9-16), greater ketone conversions are observed for water than for Gly. Thus for example using ( $p$ $\mathrm{OMe}) \mathrm{C}_{6} \mathrm{H}_{4} \mathrm{CN}$ formed $3 f$ in a modest $32 \%$ yield in Gly vs $84 \%$ in water (entries 9-10). This difference could be attributed to the different solubilities that these solid nitriles may display in the different solvents employed. Nevertheless, results summarized in Table 2 indicate an excellent substrate scope and functional

Table 2. Addition of PhLi to various nitriles (1a-i) on glycerol or water. ${ }^{\left[{ }^{\text {a] }}\right.}$

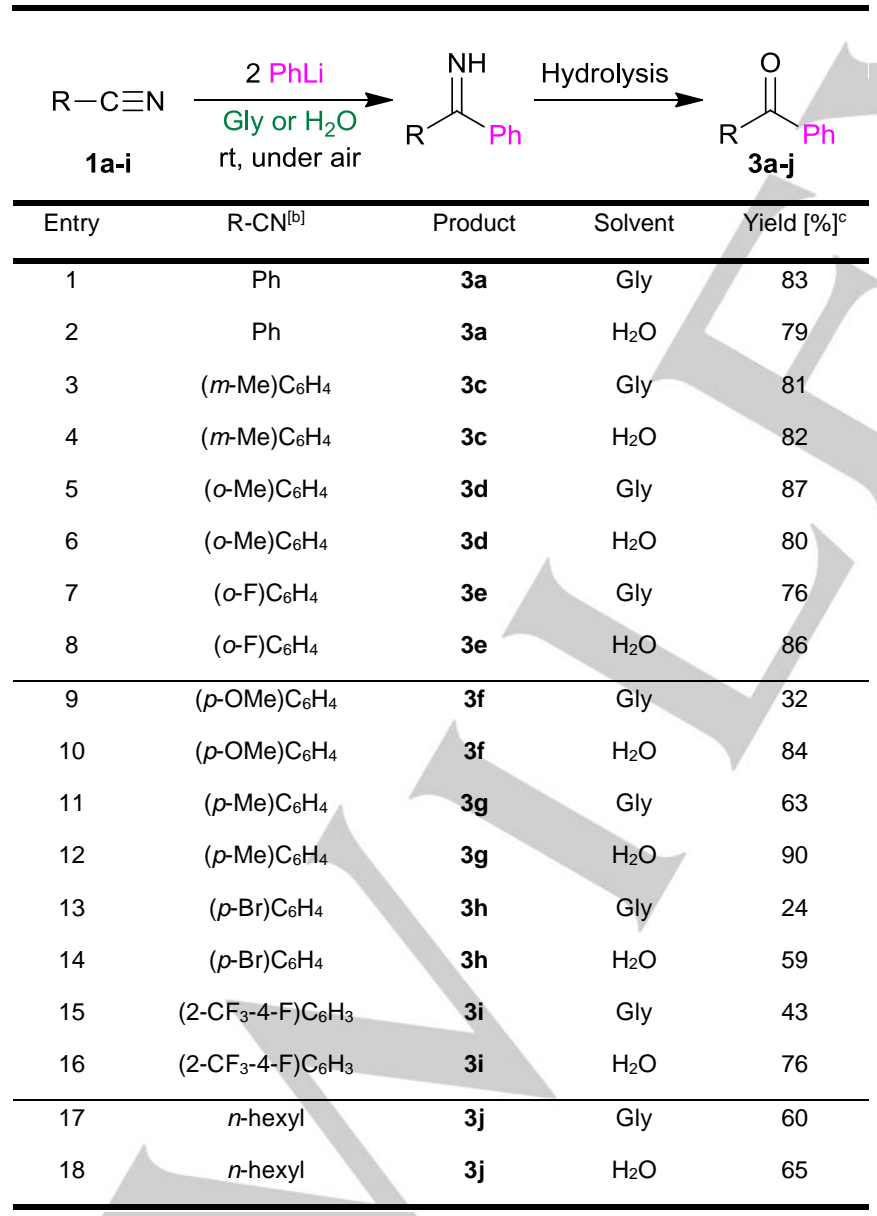

[ [a] Reactions were performed under air, at ambient temperature and using $0.5 \mathrm{~g}$ of the solvent. A commercial solution of PhLi (1.9 M in dibutyl ether) was added. ${ }^{[b]} 0.5 \mathrm{mmol}$ of the desired nitrile $(\mathbf{1 a}-\mathbf{i})$ was utilised throughout. [c] Yields determined by ${ }^{1} \mathrm{H}$ NMR spectroscopy using $\mathrm{CH}_{2} \mathrm{Br}_{2}$ as an internal standard. group tolerance, without observing other competing side reactions taking place under the conditions investigated. Steric effects on the substitution of the nitrile do not seem to have a major role, observing comparable yields in both solvents when ortho-, meta- and para-tolunitrile were employed (entries 3-6 and 11-12). The addition of $\mathrm{PhLi}$ to a purely aliphatic nitrile (hexanenitrile) furnished the aryl-alkyl-substituted ketone (1phenylhexan-1-one, $3 \mathbf{j})$ in either Gly $(60 \%$, entry 17$)$ or water $(65 \%$, entry 18$)$ whereas no addition product can be detected when acetonitrile is employed. This lack of reactivity is consistent with the high solubility of this nitrile in both solvents, precluding "on water" or "on Gly" conditions. ${ }^{[18]}$ It should be noted that contrastingly, hexanenitrile does not dissolve in Gly.

Recent reports have revealed along with increasing yields, a considerable rate acceleration can be observed in "on water" reactions when water insoluble reagents are stirred vigorously for a short period of time in pure water. ${ }^{[7 b, 8]}$ While this "on water" catalysis is still to be fully understood, it has been proposed that trans-phase $\mathrm{H}$-bonding at water-organic interfaces, promoted by "dangling" $\mathrm{OH}$ groups can be responsible. ${ }^{[19]}$ Later studies by Beattie and McErlean suggest an alternative explanation, attributing this "on water" effect to a proton transfer across the organic/water interphase. ${ }^{[20]}$

For Gly, studies using broadband vibrational sum frequency generation (VSFG) spectroscopy have shown that unlike water, the surface of pure Gly is almost "flat" without the presence of "dangling" $\mathrm{OH}$ groups to protrude out into the vapour phase. ${ }^{[21]}$ However, analysis on salty $\mathrm{NaBr}$ and $\mathrm{Nal}$ Gly solutions have revealed that bromide and iodide anions perturb the interfacial gly organization in a similar manner to that found in aqueous halide salt solutions, leading to an increase of the "dangling" $\mathrm{OH}$ groups at the interphase. This made us ponder whether using salty Gly solutions we could mimic the ketone conversions observed in water, focusing on particular in the reaction of $(p$ $\mathrm{OMe}) \mathrm{C}_{6} \mathrm{H}_{4} \mathrm{CN}$ and $\mathrm{PhLi}$, which works well in water but poorly in neat gly ( $84 \%$ vs $32 \%$ yields for ketone $3 \mathbf{f}$, Table 2, entries $9-10$; Scheme 3). Interestingly, using a $1: 8 \mathrm{NaCl}$ to Gly molar ratio solution $^{[22]}$ as a reaction medium lead to slightly lower conversions than when using neat Gly, affording $\mathbf{3 f}$ in a modest $22 \%$ yield (see SI for details), suggesting that perturbing the interfacial Gly organization does not seem to affect the efficiency of the addition process (Scheme 3). Further support was found when performing the addition of $\mathrm{PhLi}$ to $\mathrm{PhCN}$ in this salty Gly solution which gave ketone $\mathbf{3 a}$ in a $77 \%$, only slightly lower than using neat Gly (83\%, Table 2 entry 1$)$.

For comparison we also assessed this reaction using $\mathrm{H}_{2} \mathrm{O} /$ Gly mixtures for the reaction of $(p-\mathrm{OMe}) \mathrm{C}_{6} \mathrm{H}_{4} \mathrm{CN}$ and $\mathrm{PhLi}$ to form ketone 3f. As shown in Scheme 3, using a 1:1 mixture gave $3 \mathbf{f}$ in an $58 \%$ yield, which is greater than that observed in neat Gly but lower than in neat water. Contrastingly, using a $10 \mathrm{H}_{2} \mathrm{O} / 1 \mathrm{Gly}$ mixture led to the formation of $\mathbf{3 f}$ in an improved $70 \%$ yield (see SI for details). While these differences could be related to the different dynamics of the complex $\mathrm{H}$-bonding networks in these mixtures, ${ }^{[23]}$ the different solubilities of the solid nitrile $(p-\mathrm{OMe}) \mathrm{C}_{6} \mathrm{H}_{4} \mathrm{CN}$ in these solvent systems may also be key. 


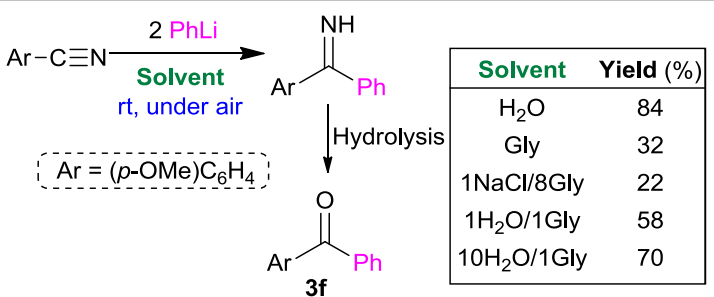

Scheme 3 Assessing the formation of $3 f$ in $\mathrm{NaCl} / \mathrm{Gly}$ and $\mathrm{H}_{2} \mathrm{O}$ /Gly mixtures. Yields determined by ${ }^{1} \mathrm{H}$ NMR spectroscopy using $\mathrm{CH}_{2} \mathrm{Br}_{2}$ as an internal standard.

Next, we extended this greener and air-tolerant protocol to other arylithium reagents, containing both electron-donating [Me (entries 1-2); $\mathrm{MeO}$ (entries 5-6)] or electron-withdrawing $\left[\mathrm{CF}_{3}\right.$ (entries 7-8)] substituents (see Table 3). Thus, benzonitrile (1a) was chosen as the benchmark reagent for this study working under the previously optimised reaction conditions ( 2 eq. of $\mathrm{RLi}$, ambient temperature, under air) with Gly or water as reaction media. As previously observed in Table 2, addition reactions took place instantaneously ( $3 \mathrm{~s}$ ) to benzonitrile furnishing the non-symmetric diarylketones $\mathbf{3 c , k - m}$ in good yields (43-95\%) and remarkable chemoselectivites, as no by-products were seen in the reaction crudes. In general, for these reactions Gly appeared to be a superior solvent, with the most noticeable effect on the yield of $\mathbf{3}$, which decreases drastically from $93 \%$ using Gly to $45 \%$ in water (entries 5-6, Table 3).

Table 3. Addition of different aryllithium (ArLi) reagents to benzonitrile (1a) "on" glycerol or water. ${ }^{[a]}$

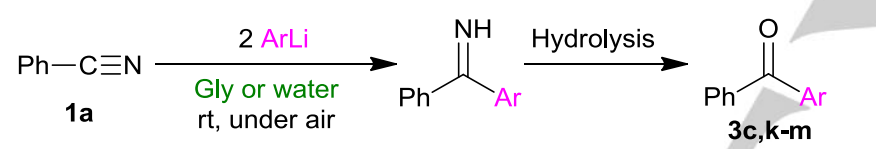

\begin{tabular}{|c|c|c|c|c|}
\hline Entry & $\operatorname{ArLi} i^{[b]}$ & Product & Solvent & Yield $[\%]^{[c]}$ \\
\hline 1 & $(m-\mathrm{Me}) \mathrm{C}_{6} \mathrm{H}_{4}$ & $3 c$ & Gly & 86 \\
\hline 2 & $(m-\mathrm{Me}) \mathrm{C}_{6} \mathrm{H}_{4}$ & $3 c$ & $\mathrm{H}_{2} \mathrm{O}$ & 79 \\
\hline 3 & $(m-\mathrm{F}) \mathrm{C}_{6} \mathrm{H}_{4}$ & $3 k$ & Gly & 59 \\
\hline 4 & $(m-\mathrm{F}) \mathrm{C}_{6} \mathrm{H}_{4}$ & $3 k$ & $\mathrm{H}_{2} \mathrm{O}$ & 69 \\
\hline 5 & $(0-\mathrm{OMe}) \mathrm{C}_{6} \mathrm{H}_{4}$ & 31 & Gly & 93 \\
\hline 6 & $(o-\mathrm{OMe}) \mathrm{C}_{6} \mathrm{H}_{4}$ & 31 & $\mathrm{H}_{2} \mathrm{O}$ & 43 \\
\hline 7 & {$\left[3,5-\left(\mathrm{CF}_{3}\right)_{2}\right] \mathrm{C}_{6} \mathrm{H}_{3}$} & $3 m$ & Gly & 79 \\
\hline 8 & {$\left[3,5-\left(\mathrm{CF}_{3}\right)_{2}\right] \mathrm{C}_{6} \mathrm{H}_{3}$} & $3 m$ & $\mathrm{H}_{2} \mathrm{O}$ & 77 \\
\hline
\end{tabular}

[a] Reactions were performed under air, at ambient temperature and using 0.5 $\mathrm{g}$ of the solvent. $0.5 \mathrm{mmol}$ of benzonitrile (1a) was utilised throughout. ${ }^{[b]} \mathrm{See}$ Experimental Section for synthesis of ArLi. [c] Yields determined by ${ }^{1} \mathrm{H}$ NMR spectroscopy using $\mathrm{CH}_{2} \mathrm{Br}_{2}$ as an internal standard.

Despite these similar performances in water and Gly, a key difference between these solvents is the greater resistance towards hydrolysis of ArLi in the latter. This was evidenced when PhLi was added to the solvent and allowed to stir for 15 seconds before introducing nitrile 1a. Astonishingly, while only traces of 3a were detected when water was employed, in Gly $\mathbf{3} \mathbf{a}$ is formed in a $74 \%$ yield (Scheme 4 ), which is comparable to that observed when the order of addition is reversed (83\%, Table 2 , entry 1).

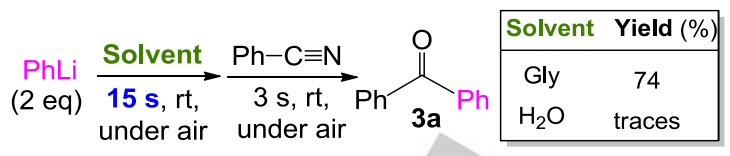

Scheme 4 Assessing the formation of $\mathbf{3 a}$ in water and Gly when the order of addition of reagents is reversed. Yields determined by ${ }^{1} \mathrm{H}$ NMR spectroscopy using $\mathrm{CH}_{2} \mathrm{Br}_{2}$ as an internal standard.

Intrigued by these findings we pondered whether Gly could also be used as a solvent for the addition of aryllithiums to ketones under air, a reactivity that we have previously reported using water and Gly-based DESs. Pleasingly, tertiary alcohols 4a-c were obtained in good yields (56-80\%) as the result of the chemoselective arylation of benzophenone, acetophenone and trifluoromethyl acetophenone respectively using $\mathrm{PhLi}$ (2 eq) and bulk Gly as the reaction media (see Scheme 5).

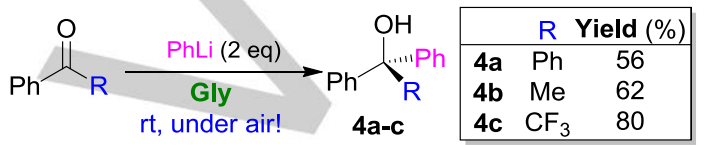

Scheme 5 Addition of PhLi to different ketones in Gly, at ambient temperature and in the presence of air. Yields determined by ${ }^{1} \mathrm{H}$ NMR spectroscopy using $\mathrm{CH}_{2} \mathrm{Br}_{2}$ as an internal standard.

\section{Conclusions}

In summary, we have demonstrated that, like water, Gly can function as an environmentally-friendly reaction medium for the ultrafast and chemoselective addition of arylithium reagents to nitriles under standard bench reaction conditions (ambient temperature and under air), that for almost a century have been out of bounds in polar organometallic chemistry. Notably working under heterogeneous conditions (since the starting nitriles are insoluble in Gly or water) allowed the smooth nucleophilic addition of organolithium reagents to nitriles either "on glycerol" or "on water", respectively. Moreover, the unprecedented use of Gly (low-cost and renewable feedstock) in polar organometallic chemistry unlocks countless scenarios for developing more sustainable main-group-mediated organic syntheses.

\section{Experimental Section}

General procedure for the addition reactions of PhLi with nitriles in alternative solvent: Syntheses were performed under air and at room temperature. In a glass tube, the appropriate nitrile $(0.5 \mathrm{mmol})$ was added to the corresponding alternative solvent $(0.5 \mathrm{~g})$ under air, followed by the addition of $\mathrm{PhLi}(1 \mathrm{mmol})$ at room temperature, and the reaction mixture was stirred for 2-3 seconds. The reaction was then stopped by addition of a saturated solution of the Rochelle salt (sodium potassium tartrate tetrahydrate). The reaction mixture was transferred to a round bottom flask, $5 \mathrm{~mL}$ of $2 \mathrm{M} \mathrm{HCl}$ was added and heated at $100{ }^{\circ} \mathrm{C}$ for 30 min After cooling down to room temperature, the reaction mixture was neutralised by addition of $\mathrm{NaHCO}_{3}$ and the organic products were extracted with dichloromethane $(3 \times 5 \mathrm{~mL})$. The combined organic extracts were dried over $\mathrm{MgSO}_{4}$ and the solvent removed under reduced pressure. Yields of the reaction crudes were determined by ${ }^{1} \mathrm{H}$ NMR methodology using dibromomethane as an internal standard. The identity of obtained ketones $3 \mathbf{a},,^{[24]} \mathbf{3 b},{ }^{[25]} \mathbf{3 c},{ }^{[24]} \mathbf{3 d},{ }^{[24]} \mathbf{3 e},{ }^{[24]} \mathbf{3 f},{ }^{[24]} \mathbf{3 g},{ }^{[24]} \mathbf{3 h},{ }^{[24]}$ $\mathbf{3} \mathbf{j},{ }^{[26]} \mathbf{3 k},{ }^{[27]} \mathbf{3},{ }^{[24]} \mathbf{3} \mathbf{m}^{[28]}$ was assessed by comparison of their ${ }^{1} \mathrm{H}$ and ${ }^{13} \mathrm{C}$ spectroscopic data with those reported in the literature. $3 \mathbf{i}$ was isolated 
and fully characterized, see SI for details. All reactions were done in triplicate to ensure good reproducibility of obtained yields.

General procedure for synthesis of aryllithium reagents: In addition to commercially available $\mathrm{PhLi}$, other aryllithium reagents were tested as reagents that can undergo addition to benzonitrile. These were prepared under protective argon atmosphere using standard Schleck techniques and solvent dried by heating to reflux over sodium benzophenone ketyl and then distilled under nitrogen prior to use. To a diethyl ether solution of the chosen aryl iodide $\left(6 \mathrm{mmol}\right.$ in $2.2 \mathrm{~mL}$ of $\left.\mathrm{Et}_{2} \mathrm{O}\right)$ at $-78^{\circ} \mathrm{C} n$ butyllithium ( $6 \mathrm{mmol}, 1.6 \mathrm{M}$ in hexanes) was added drop-wise. The reaction mixture was warmed up and stirred at room temperature for $2 \mathrm{~h}$ before it was used as a $1 \mathrm{M}$ solution of aryllithium reagent for the addition reactions. Following additions were, as described above, performed under air in triplicate.

General procedure for the addition reactions of PhLi with ketones in glycerol: Syntheses were performed under air and at room temperature. In a glass tube, the appropriate ketone $(0.5 \mathrm{mmol})$ was dissolved in glycerol $(0.5 \mathrm{~g})$ under air, to which PhLi $(1 \mathrm{mmol})$ was added at room temperature, and the reaction mixture was stirred for 2-3 seconds. The reaction was then stopped by addition of a saturated solution of the Rochelle salt (sodium potassium tartrate tetrahydrate) and organic products were extracted with dichloromethane $(3 \times 5 \mathrm{~mL})$. The combined organic extracts were dried over $\mathrm{MgSO}_{4}$ and the solvent removed under reduced pressure. Yields of the reaction crudes were determined by ${ }^{1} \mathrm{H}$ NMR spectroscopy using dibromomethane as an internal standard. The identity of obtained tertiary alcohols $\mathbf{4 a},{ }^{[29]} \mathbf{4} \mathbf{b}^{[30]}$ and $\mathbf{4} \mathbf{c}^{[31]}$ was assessed by comparison of their ${ }^{1} \mathrm{H}$ and ${ }^{13} \mathrm{C}$ spectroscopic data with those reported in the literature.

Comparison of the stability of phenyllithium in glycerol and water: Phenyllithium ( $1 \mathrm{mmol}, 0.53 \mathrm{~mL}, 1.9 \mathrm{M}$ solution) was added to glycerol or water $(0.5 \mathrm{~g})$, respectively, and stirred under air. After 15 seconds, benzonitrile $(0.5 \mathrm{mmol}, 0.051 \mathrm{~g})$ was added under air, at room temperature, and the reaction mixture was stirred for $2-3$ seconds. The reaction was then stopped by addition of a saturated solution of the Rochelle salt and the product was hydrolysed, isolated, identified and quantified as previously described.

\section{Acknowledgements}

We are indebted to the MINECO of Spain (Projects CTQ201451912-REDC and CTQ2016-75986-P), the Gobierno del Principado de Asturias (Project GRUPIN14-006) and the Fundación BBVA for the award of a "Beca Leonardo a Investigadores y Creadores Culturales 2017" to JGA. We also thank the EPSRC (EP/N011384/1) and the Society of Spanish Researchers in the UK (SRUK) and the Fundación Santander (Emerging Talent Award to EH). The Scottish Funding Council are thanked for a PECRE award to MF to enable an exchange visit to Oviedo University.

Keywords: Organolithium Reagents $•$ Glycerol $\bullet$ Water $\bullet$ Green Chemistry • Nitriles •

[1] For an insightful frontier article on the pivotal role of organolithium chemistry, see: V. Capriati, F. M. Perna, A. Salomone, Dalton Trans. 2014, 43, 14204

[2] (a) The Chemistry of Organolithium Compounds (Eds. Z. Rappoport, I. Marek), Patai Series, Wiley, Chichester, 2004; (b) J. Clayden, Organolithiums: Selectivity for Synthesis, Pergamon, Elsevier Science Ltd., Oxford, 2002.

[3] V. Capriati, J. García-Álvarez, E. Hevia, Eur. J. Org. Chem. 2015, 6779 and references therein.
[4] For recent reviews in DESs see: (a) M. Francisco, A. van den Bruinhorst, M. C. Kroon, Angew. Chem. Int. Ed. 2013, 52, 3074; (b) E. L. Smith, A. P. Abbott, K. S. Ryder, Chem. Rev. 2014, 114, 11060; (c) J. García-Álvarez, Eur. J. Inorg. Chem. 2015, 5147; (d) D. A. Alonso, A. Baeza, C. Chinchilla, R. G. Guillena, I. M. Pastor, D. J. Ramón, Eur. J. Org. Chem. 2016, 612

[5] (a) C. Vidal, J. García-Álvarez, A. Hernán-Gómez, A. R. Kennedy, E. Hevia, Angew. Chem. Int. Ed. 2014, 53, 5969; (b) L. Cicco, M. J. Rodríguez-Álvarez, F. M. Perna, J. García-Álvarez, V. Capriati, Green Chem. 2017, 19, 3069

[6] C. Vidal, J. García-Álvarez, A. Hernán-Gómez, A. R. Kennedy, E. Hevia, Angew. Chem. Int. Ed. 2016, 55, 16145.

[7] (a) L. Cicco, S. Sblendorio, R. Mansueto, F. M. Perna, A. Salome, S Florio, V. Capriati, Chem. Sci. 2016, 7, 1192; (b) G. Dilauro, M. Dell'Aera, P. Vitale, V. Capriati, F. M. Perna, Angew. Chem. Int. Ed 2017, 56, 10200. For related studies using DESs see also: (c) V. Mallardo, R. Rizzi, F. C. Sassone, R. Mansueto, F. M. Perna, A Salomone, V. Capriati, Chem. Commun. 2014, 50, 8655; (d) F. C. Sassone, F. M. Perna, A. Salomone, S. Florio, V. Capriati, Chem. Commun. 2015, 51, 9459.

[8] (a) A. Chanda, V. V. Fokin, Chem. Rev. 2009, 109, 725; (b) R. M. Butler, A. G. Coyne, J. Org. Chem. 2015, 80, 1809; (c) R. N. Buttler, A. G. Coyle, Org. Biomol. Chem. 2016, 14, 9945.

[9] (a) V. Pace, P. Hoyos, L. Castoldi, P. Domínguez de María, A. R Alcántara, ChemSusChem 2012, 5, 1369; (b) J. Yang, J.-N. Tan, Y. Gu, Green Chem. 2012, 14, 3304; (c) D. M. Alonso, S. G. Wettstein, J. A. Dumesic, Green Chem. 2013, 15, 584.

[10] The biodiesel industry produces a large excess of glycerol (ca. $100 \mathrm{~kg}$ of glycerol per ton of biodiesel): N. Rahmat, A. Z. Abdullah, A. R. Mohamed, Renew. Sustain. Energy Rev. 2010, 14, 987.

[11] (a) Y. Gu, F. Jérôme, Green Chem. 2010, 12, 1127; (b) A. E. DíazÁlvarez, J. Francos, B. Lastra-Barreira, P. Crochet, V. Cadierno, Chem. Commun. 2011, 47, 6208; (c) F. Chahdoura, I. Favier, M. Gómez, Chem. Eur. J. 2014, 20, 10884

[12] (a) J. Francos, V. Cadierno, Green Chem. 2010, 12, 1552; (b) C. Vidal, J. García-Álvarez, Green Chem. 2014, 16, 3515; (c) M. Rodríguez Rodríguez, E. Gras, M. A. Pericàs, M. Gómez, Chem. Eur. J. 2015, 21, 18706; (d) M. Rodríguez-Rodríguez, P. Llanes, C. Pradel, M. A. Pericàs, M. Gómez, Chem. Eur. J. 2016, 22, 18247.

[13] Note that in conventional anaerobic organolithium chemistry this reaction produces iminolithium compounds with stacked ring structures. See (a) D. Barr, W. Clegg, R. E. Mulvey, R. Snaith, J. Chem. Soc Chem. Commun. 1984, 79; (b) D. Barr, W. Clegg, R. E. Mulvey, R Snaith, K. Wade, J. Chem. Soc. Chem. Commun. 1985, 295; (c) D. R. Armstrong, D. Barr, W. Clegg, R. E. Mulvey, R. Snaith, K. Wade, D. Reed, J. Chem. Soc. Dalton Trans. 1987, 1071.

[14] In contrast, the double addition of $R L i / R M g X$ reagents to nitriles has been recently reported "in water" and "on water" conditions (see ref. 7b).

[15] See SI for experimental and spectroscopic details.

[16] J. A. Padró, L. Saiz, E. Guàrdia, J. Mol. Struct. 1997, 416, 243.

[17] Similar trend has been previously reported by us in the addition of $\mathrm{RMgX}$ to imines in different eutectic mixtures, ref. 6 .

[18] While in our hands formation of acetophenone, as the result of addition PhLi to MeCN under the conditions of our study $\left(\mathrm{H}_{2} \mathrm{O}\right.$ or Gly as solvent, rt, under air), could not be detected, it should be noted that Capriati has reported the sequential addition of $\mathrm{PhLi}$ and allylMgCl in water to acetonitrile furnishing the relevant tertiary allyl amine in a remarkable $70 \%$ yield, see reference $7 \mathrm{~b}$.

[19] Y. Yung, R. A. Marcus, J. Am. Chem. Soc., 2007, 129, 5492

[20] (a) J. K. Beattie, C. S. P. McErlean, C. W. Phippen, Chem. Eur. J. 2010 16, 8972. (b) K. D. Beare, C. S. P. McErlean, Org. Biomol. Chem. 2013 $11,2452$.

[21] Z. Huang, W. Hua, D. Verreault, H. C. Allen, J. Phys. Chem. A, 2013 $117,6346$.

[22] A. P. Abbott, C. D'Agostino, S. J. Davis, L. F. Gladden, M. D. Mantle, Phys. Chem. Chem. Phys. 2016, 18, 25528.

[23] For a molecular dynamics simulation study on $\mathrm{H}$-bonding analysis of glycerol aqueous solutions see: C. Chen, W. Z. Li, Y. C. Song, J. Yang, J. Mol. Liq. 2009, 146, 23.

[24] M. Li, C. Wang, H. Ge, Org. Lett. 2011, 13, 2062. 
[25] J. A. Murphy, A. G. J. Commeureuc, T. N. Snaddon, T. M. McGuire, T. A. Khan, K. Hisler, M. L. Dewis, R. Carling, Org. Lett. 2005, 7, 1427.

[26] J. Ruan, O. Saidi, J. A. Iggo, J. Xiao, J. Am. Chem. Soc. 2008, 130 , 10510.

[27] A. T. Biju, F. Glorius, Angew. Chem. Int. Ed. 2010, 49, 9761.

[28] C. J. Rohbogner, C. R. Diène, T. J. Korn, P. Knochel, Angew. Chem. Int. Ed. 2010, 49, 1874.

[29] T. Maekawa, H. Sekizawa, K. Itami, Angew. Chem. Int. Ed. 2011, 50, 7022.

[30] M. Hatano, S. Suzuki, K. Ishihara, J. Am. Chem. Soc. 2006, 128, 9998.

[31] J. R. White, G. J. Price, P. K. Plucinski, C. G. Frost, Tetrahedron Lett. 2009, 50, 7365 . 
Entry for the Table of Contents (Please choose one layout)

Layout 1:

\section{FULL PAPER}

\section{Hooked on Glycerol!}

Using glycerol as a sustainable and green reaction medium enables the efficient chemoselective addition of aryllithium reagents to nitriles at room temperature in air, edging closer towards reaching air- and moisturecompatible polar organometallic chemistry

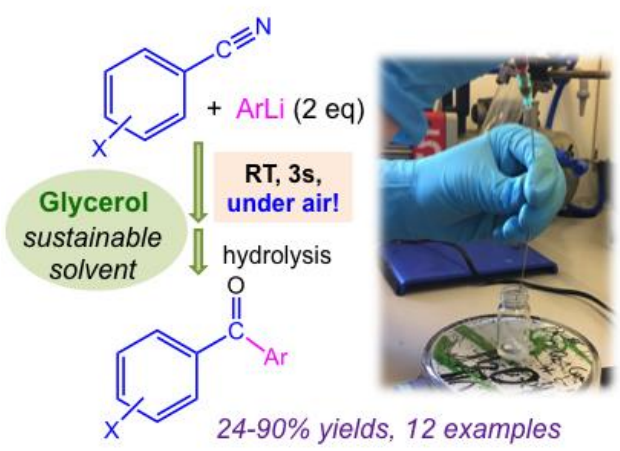

M. J. Rodríguez-Álvarez, J. GarcíaÁlvarez, * M. Uzelac, M. Fairley, C. T. O'Hara and E. Hevia*

Page No. - Page No.

Introducing Glycerol as a Sustainable Solvent to Organolithium Chemistry: Ultrafast Chemoselective Addition of Aryllithium Reagents to Nitriles Under Air and at Ambient Temperature 